\title{
Esophagectomy Without Mortality: What Can Surgeons Do?
}

\author{
Simon Law
}

Received: 15 July 2009 / Accepted: 25 August 2009

(C) 2009 The Society for Surgery of the Alimentary Tract

\section{Introduction}

Surgical resection remains the mainstay treatment for patients with localized esophageal cancer. It is justified only when acceptably low morbidity and mortality rates can be achieved; otherwise, the benefits gained by those who survive the operation are offset by the deaths of others. ${ }^{1} \mathrm{~A}$ volume-outcome relationship is evident in complex surgery like esophagectomy; in dedicated high-volume centers, resection mortality rate of $2-3 \%$ can be achieved. ${ }^{2-8}$ It is also true that the overall mortality rate still approximates $10 \%$ when results from multicenter trials and national figures are included. ${ }^{9,10}$ It is thus important to appraise the factors leading to such diverse results, and seek ways to improve this.

The outcome of esophagectomy is mainly related to: (1) selecting appropriate patients for resection and optimizing the patients' physiologic status before surgery, (2) choice of surgical techniques and their execution, and (3) perioperative care.

Based on a presentation delivered at Festschrift for Professor Tom DeMeester Los Angeles May 2008

S. Law $(\bowtie)$

Department of Surgery, Li Ka Shing Faculty of Medicine,

The University of Hong Kong, Queen Mary Hospital,

102 Pokfulam Road,

Hong Kong, China

e mail: slaw@hku.hk

\section{Risk Assessment and Patient Selection for Esophagectomy}

Assessing a patient's fitness is often based on the surgeons' experience and intuition rather than an exact science. Objective scores have been developed to aid this process using various statistical methods. ${ }^{11,12}$ Using a composite score compromising general status, poor cardiac, hepatic, and respiratory function as independent predictors of postoperative death, one group of investigators reduced postoperative mortality rate from $9.4 \%$ to $1.6 \%{ }^{3,12}$ It is uncertain if patient selection based on a "strict" mathematical scoring system is better than that of surgeons and anesthesiologists' assessments alone. They are more likely to be complimentary to each other. When patients with squamous cell cancers and adenocarcinomas are compared, they may have different risk profiles, in part related to their dissimilar etiological factors. The main risks for the former group seem to be pulmonary and hepatic, related to smoking and alcohol consumption, while for the latter, cardiac risk factors may be more important, associated with obesity. ${ }^{3}$ The focus of perioperative care has to be adjusted for these two types of patients.

Once a patient is selected for surgical resection, optimizing his or her physiological status should be an important goal of preoperative preparation. However, what one could achieve is usually limited. Patients with impaired liver reserve related to chronic alcoholism or hepatitis cannot be made better, and pulmonary damage from chronic smoking is mostly irreversible. Patients should still be made to stop smoking and abstain from alcohol and intensive chest physiotherapy applied. Patients with reversible airway obstructive disease should have their bronchodilator therapy optimized. One potentially 
"treatable" adverse factor is cardiac ischemia; when significant coronary atherosclerotic stenosis is found, revascularization by percutaneous coronary angioplasty is a definite beneficial therapeutic strategy. Patients with high-grade esophageal malignant stricture may have lost substantial amount of their body weight. Providing high caloric and high protein dietary supplement, even in the form of nasogastric tube feeding, will improve their general physique in a relatively short time.

\section{Choice of Surgical Procedure}

There are different surgical approaches for esophagectomy, including the transhiatal approach, esophagectomy via a left or right thoracotomy, or in recent years, minimally invasive surgery involving thoracoscopy and/or laparoscopy. There is also a choice of the organ (stomach, colon, and jejunum) used to restore intestinal continuity, the route taken to place the conduit (intrathoracic, orthotopic, retrosternal, or subcutaneous), and the location of the esophageal anastomosis (neck or chest). The intended extent of lymphadenectomy plays an important role in this decision-making. When considering radical lymphadenectomy, the physiological reserve of the patient has to be taken into account, as such an operation may not be appropriate in a high-risk patient. ${ }^{13}$ The various combinations of surgical options have to be carefully chosen for individual patient.

The debate on whether a transthoracic or a transhiatal resection is to be used has been ongoing. Proponents of transhiatal resection believe that surgical resection for esophageal cancer is mostly palliative, and a cure is a chance phenomenon for only those with very early tumors. The operating time is also shorter, and postoperative morbidity is less. Equivalent survival to transthoracic resection is claimed. ${ }^{14}$ Conversely, surgeons who practice transthoracic esophagectomy consider the open approach to be safer, with less chance of injury to the tracheo-bronchial tree, thoracic duct, recurrent laryngeal nerves, azygous vein, and aorta. ${ }^{15}$ A more thorough lymphadenectomy leads to better staging and also longer survival, but at the same time, extensive lymphadenectomy may lead to more postoperative complications.

The largest randomized trial comparing the two approaches to date compared 106 patients who underwent transhiatal esophagectomy with 114 patients who had the transthoracic approach for mid-lower third/cardia adenocarcinomas. Pulmonary complication rates were $27 \%$ in the former group compared to $57 \%$ in the later. Ventilation time, intensive care, and hospital stay were longer in the transthoracic group. There were, however, no significant differences in in-hospital mortality at $2 \%$ and $4 \%$. Significantly more lymph nodes were dissected in the transthoracic group (16 vs. 31). There was a trend toward a survival benefit with the transthoracic approach at 5 years: disease-free survival was $27 \%$ compared with $39 \%$, overall survival was $29 \%$ compared with $39 \%$. There was also no difference in quality of life in the long run between both groups. ${ }^{16}$ A subsequent follow-up study showed that for Siewert type I tumors (true esophageal), an estimated survival benefit of $14 \%$ (5-year survival $37 \%$ vs. $51 \%$ ) was evident (though statistically insignificant), while this was absent for type II (true cardia/gastroesophageal junction) cancers (5-year survival $31 \%$ and $27 \%$ ). In addition, in patients with limited nodal disease (one to eight metastatic nodes), a significant survival benefit existed (5-year survival $23 \%$ vs. $64 \%$ ). This effect was not found for patients without nodal metastases or in those with more than eight positive nodes, suggesting that extended lymphadenectomy provides survival benefits in patients with limited spread. ${ }^{17}$ Further convincing evidence for the benefit of lymphadenectomy is also shown in a recent international multicenter study involving 2,303 patients from both western and eastern centers, which demonstrated on multivariate analysis that both the number of involved nodes as well as the number of nodes removed at operation were of prognostic significance. ${ }^{18}$

It does seem that the advent of transhiatal esophagectomy came at a time when esophagectomy was a high-risk operation with high mortality rates, and this "less invasive" method probably contributed to reducing overall death rates. With improvement in surgical techniques and perioperative care, it seems that in most experienced centers, when selected appropriately, both procedures can be carried out safely, and the margin of benefit in reducing morbidity for most patients with the transhiatal operation is not overwhelming. There is also increasing evidence of the benefits of radical lymphadenectomy in recent years. With these considerations, the transthoracic approach with radical nodal dissection should be the procedure of choice in patients with good risk and limited localized disease.

In Asian countries, the transhiatal vs. transthoracic debate has not been a major controversy. This is because the type of cancers are mostly advanced tumors of the middle and upper esophagus. In these patients, from a purely technical and safety standpoint, the transhiatal method is much less suitable except in early tumors. Mediastinal lymph node dissection is also deemed to be more important, given the more proximally located tumors, and these stations cannot be reached from the abdomen. Thus, transthoracic resection remains the surgical approach of choice.

Minimally invasive surgery (MIS) as applied to esophagectomy, like the transhiatal approach, aims at reducing the trauma of surgical access further. What is potentially better than the transhiatal approach is that when a thoracoscopic 
phase is used, a thorough mediastinal nodal dissection can be performed as well. By reducing the size of the wounds, cardiopulmonary complications may be further reduced, without sacrificing the extent of lymphadenectomy. Indeed, with the magnification offered by thoracoscopy, some investigators have claimed better and more meticulous nodal dissection with the MIS approach. ${ }^{19,20}$

Many different MIS approaches in esophagectomy have been devised, including various combinations of thoracoscopy, laparoscopy, mediastinoscopy, and laparoscopicassisted (with minilaparotomy or hand-port devices) or thoracoscopic-assisted methods (with minithoracotomy). The myriad of surgical methods implies a lack of consensus on which is superior. ${ }^{21}$ The most popular is perhaps thoracoscopic esophagectomy with gastric mobilization via a laparotomy and cervical esophago-gastrostomy. ${ }^{20,22-25}$ Most performed the thoracoscopic procedures using a lateral position, though some also advocated a prone position for improved exposure, since the lung and blood naturally fall away from the operating field. ${ }^{25-27}$

Contraindications for thoracoscopic procedures may include extensive pleural adhesions and bulky or locally infiltrative tumors, especially those in close proximity with the tracheo-bronchial tree. Some surgeons do not recommend the procedure in patients with prior irradiation because tissue planes may be obscured, ${ }^{28}$ while others do not find this prohibitive. ${ }^{23}$ In many series, early-stage cancers or patients with high-grade dysplasia were preferentially selected, partly because of the technical ease with which these tumors can be resected. ${ }^{29,30}$ In a large series of 222 patients, two thirds of patients had cancer of stage II and below; $21 \%$ had high-grade dysplasia. ${ }^{31}$

The lack of tactile control is probably a contributory factor in some intraoperative complications, such as bleeding from the azygous $\operatorname{vein}^{32}$ and from intercostal vessel, ${ }^{33}$ injury to the aorta, ${ }^{34}$ tracheo-bronchial tree, ${ }^{35,36}$ and recurrent laryngeal nerve. ${ }^{37}$ On the contrary, the increased magnification and excellent visualization offered by thoracoscopy might in fact help lessen complications. Less blood $\operatorname{loss}^{22}$ and reduction in transient recurrent laryngeal nerve palsy from $80 \%$ to $18 \%$ were reported. ${ }^{38}$ As surgical techniques mature and instrumentation improves, the chance of intra-operative mishaps will likely reduce.

Most published studies include small number of patients, with the exception of a few which included more than 100 patients. $^{23,25,27,31,39}$ Direct comparisons of results with patients who underwent conventional esophagectomy, either in concurrent or historical cohorts of patients, are also uncommon. When benefits are found, these included blood loss, shortened intensive care or hospital stay, analgesic requirement, spirometric and pulmonary function derangements, ${ }^{20,40-42}$ and biochemical changes. ${ }^{43}$ Some authors also reported less morbidities, such as less recurrent laryngeal nerve injury and pulmonary ${ }^{38}$ and cardiac complications, ${ }^{35,44}$ but certainly these advantages are not universally accepted. ${ }^{39}$ Short- to medium-term quality-oflife scores are probably only comparable to that of the open procedure. ${ }^{45,46} \mathrm{~A}$ learning curve exists for such complicated procedures, ${ }^{38,47}$ and for most series, the full technical potential may not have been realized.

The place of MIS esophagectomy remains controversial and is evolving. What is certain is that, with the complexity, these techniques should be investigated in centers experienced with open method of esophagectomy.

The tumor resection phase of an esophagectomy must be carried out with care; direct damage to important structures such as the tracheo-bronchial tree or aorta will have disastrous immediate consequences, while injuring the thoracic duct will lead to chylothorax ${ }^{48}$ or recurrent laryngeal nerves predisposing patients to aspiration and pneumonia after surgery.

Recovery from esophagectomy depends to a large extent on the reconstructive phase. The most common surgical complication after esophagectomy is still anastomotic leak and can reach $30 \%,{ }^{49}$ although in experienced centers, leak rates of below $5 \%$ can be achieved. Most leaks are probably related to technical faults, ${ }^{11,50}$ such as tension between the conduit and the esophageal stump, ischemia of the conduit because of rough handling and poor preparation, and suboptimal anastomotic technique. The intrinsic vascular perfusion of the stomach can be enhanced by certain methods, such as "ischemic pre-conditioning," whereby partial mobilization of the gastric conduit is followed by a second-stage anastomosis later. The perfusion of the stomach could be shown to improve in the interim period. ${ }^{51}$ Although an interesting concept and potentially useful, existing wide range of leak rates (from $2-3 \%$ to $30 \%$ ) suggest much improvement could be made by other means, even without ischemic conditioning. It would perhaps be ideal if one could identify the right patients on whom to perform ischemic conditioning, so that such elaborate preparation can be selectively applied.

The actual method of anastomosis is less important than its proper application. Stapled anastomosis is popular for intrathoracic anastomosis, while the hand-sewn technique is preferred in the neck. There is no evidence from randomized trials that leak rates differ between stapled and handsewn anastomoses, but the circular stapler may give rise to more strictures. ${ }^{52}$ The linear stapler has also been advocated in the neck. One group reduced their cervical leak rate from $10-15 \%$ using a hand-sewn technique to $2.7 \%$ using linear staples with a side-to-side anastomosis. ${ }^{53}$ With experience, however, the hand-sewn method is as safe, if not more so, and certainly less expensive. Leak rate was $3 \%$ in our patients who had an intrathoracic anastomosis, 35\% of 
whom died, resulting in an overall leak-related morality of $1 \%$ out of all patients who had esophagectomy. ${ }^{50,54}$

The route of reconstruction is in part related to the surgical approach for resection. When a cervical anastomosis is chosen, a choice exists for placing the conduit in the orthotopic, retrosternal, or subcutaneous route. The subcutaneous route is rarely used because it is cosmetically unsightly. The retrosternal route has variably been shown to be associated with increased or similar cardiopulmonary morbidity and mortality rates. ${ }^{55-57}$ The retrosternal route is 2-3 cm longer compared to the orthotopic route ${ }^{58}$ but is rarely of relevance because the esophageal replacement conduit is usually of sufficient length. Some suggest that the tight space at the thoracic inlet in the neck could cause potential constriction on the conduit and recommend partial manubrium, clavicular head, and first rib resection, ${ }^{59}$ although the author has found this unnecessary.

Technical variables play an important role in the genesis of postoperative complications. Complications, such as anastomotic leaks (largely technique-related) and recurrent laryngeal nerve injury, for instance, are related to higher incidences of postoperative pulmonary morbidities. At the author's center, pulmonary complications occurred in $10 \%$ of patients without technical complications and in 38\% of patients who developed such morbidities; mortality rates were $3.3 \%$ and $9.2 \%$, respectively. ${ }^{60}$ Multivariate analyses also demonstrated that a long operating time was related to pulmonary complications, and increasing intraoperative blood loss was related to postoperative mortality. ${ }^{61}$ In sum, the meticulous and expeditious execution of an esophagectomy and its subsequent reconstruction is of paramount importance in lessening complication and mortality rates.

\section{Perioperative Care}

With adequate preoperative workup, serious cardiac events like myocardial infarction should be rare. Pulmonary complications remain the most common and serious postoperative morbidity. Most report a respiratory morbidity rate of about $20 \% .{ }^{10}$ Pneumonia and respiratory failure occur in $15.9 \%$ of our patients and are responsible for $55 \%$ of hospital deaths. Predictive factors include advanced age, supracarinal tumor location, and lengthened operating time. The increased chance of pulmonary complications associated with supracarinal tumors is in part related to the prevalence of recurrent laryngeal nerve injury, which reduces the effectiveness of glottic closure on coughing, diminishes airway protection, and predisposes to aspiration. Long-term quality of life is also impaired. ${ }^{62}$ Neoadjuvant therapy did not lead to increased morbidity. ${ }^{61}$ Measures to improve respiratory outcome include cessation of smoking preoperatively, chest physiotherapy, avoidance of recurrent laryngeal nerve injury, cautious fluid administration to avoid fluid overload, use of smaller chest tube, ${ }^{63}$ early ambulation, regular bronchoscopy, and early tracheostomy to provide easy access should there be sputum retention despite regular bronchoscopic clearance. ${ }^{64}$ Epidural analgesia is invaluable in postoperative pain relief and should be the standard of care after esophagectomy. ${ }^{65}$ In a retrospective study at the author's unit, the use of epidural analgesia led to a reduction of major pulmonary complications from $22 \%$ to $13 \%{ }^{65}$

As discussed in the previous section, anastomotic leak remains one of the most common and deleterious complications after esophagectomy. Early detection of anastomotic leaks is important so that timely intervention can be instituted; sometimes a high index of suspicion is important when other seemingly unrelated complications develop, such as atrial fibrillation. ${ }^{66}$ Atrial arrhythmia is common, affecting about $20 \%$ of patients. In itself, atrial fibrillation is benign; rather, it serves as a marker for more serious underlying pulmonary and septic surgical complications. ${ }^{66}$ Occurrence of atrial arrhythmia should prompt thorough search for a more ominous underlying cause. In 1946, in the article published by Ivor Lewis on esophagectomy, he commented on the postoperative course of one patient: "On the third day arrhythmia of the heart was present.... In the next two days his respiration increased, moist sounds developed at the bases, and he died six days after the operation." He further wrote: "I now think this case might have been saved by timely and repeated bronchoscopic suction. The cardiac arrhythmia... probably had little to do wit his death." ${ }^{67}$ Thus, the significance of atrial arrhythmia as a "complication marker" has long been recognized. Treatment principles dictate adequate drainage, whether by radiological, endoscopic, or surgical means. Recent use of a removable plastic stent in sealing anstomotic leaks holds promise as a "minimally invasive method" of leak management. ${ }^{68}$ Maintenance of nutritional status is important, preferably via the enteral route, either by a fine-bore nasoduodenal tube placed endoscopically or by feeding jejunostomy. Improvements in the management of leaks have led to reduction in leak-related mortality. At the author's unit, anastomotic leak rate was $16 \%$ in the 1960 s to $1970 \mathrm{~s}, 61 \%$ of whom died, resulting in a leak-related mortality of $9.8 \% .{ }^{54}$ In the $1980 \mathrm{~s}$, leak rate was $3.5 \%$, of whom $35 \%$ died, a leak-related mortality of $1.2 \%,{ }^{50}$ while in the late $1990 \mathrm{~s}$, leak occurred in $3.2 \%$ of patients, and none died as a result. ${ }^{69}$

Other surgical complications like chylothorax and herniation of bowel through the diaphragmatic hiatus are rare but should be recognized early, and both are corrected by surgical re-exploration. Early exploration is more likely to be successful than expectant treatment. ${ }^{70}$ 


\section{Summary}

In summary, achieving esophagectomy without mortality depends on realistic patient selection, versatility in the choice of surgical procedure, its meticulous and expeditious execution, vigilant and proactive postoperative care, timely and aggressive intervention, and most of all, multidisciplinary team work involving surgeons, anesthesiologists, intensivists, and other health care workers. An obvious volume-outcome relationship exists, ${ }^{8,71}$ but it is the dedicated care of individuals which matters most.

\section{References}

1. Wong J. Esophageal resection for cancer: the rationale of current practice. Am J Surg 1987;153:18 24

2. Law S, Kwong DL, Kwok KF, Wong KH, Chu KM, Sham JS, Wong J. Improvement in treatment results and long term survival of patients with esophageal cancer: impact of chemoradiation and change in treatment strategy. Ann Surg 2003;238:339 348.

3. Siewert JR, Stein HJ, Feith M, Bruecher BL, Bartels H, Fink U. Histologic tumor type is an independent prognostic parameter in esophageal cancer: lessons from more than 1,000 consecutive resections at a single center in the Western world. Ann Surg 2001;234:360 367.

4. Hagen JA, DeMeester SR, Peters JH, Chandrasoma P, DeMeester TR. Curative resection for esophageal adenocarcinoma: analysis of 100 en bloc esophagectomies. Ann Surg 2001;234:520 530.

5. Altorki N, Kent M, Ferrara C, Port J. Three field lymph node dissection for squamous cell and adenocarcinoma of the esophagus. Ann Surg 2002;236:177 183 .

6. Ando N, Ozawa S, Kitagawa Y, Shinozawa Y, Kitajima M. Improvement in the results of surgical treatment of advanced squamous esophageal carcinoma during 15 consecutive years. Ann Surg 2000;232:225 232.

7. Birkmeyer JD, Siewers AE, Finlayson EV, Stukel TA, Lucas FL, Batista I, Welch HG, Wennberg DE. Hospital volume and surgical mortality in the United States. N Engl J Med 2002;346:1128 1137.

8. Birkmeyer JD, Stukel TA, Siewers AE, Goodney PP, Wennberg DE, Lucas FL. Surgeon volume and operative mortality in the United States. N Engl J Med 2003;349:2117 2127.

9. Medical Research Council Oesophageal Cancer Working Party. Surgical resection with or without preoperative chemotherapy in oesophageal cancer: a randomised controlled trial. Lancet 2002;359:1727 1733.

10. Bailey SH, Bull DA, Harpole DH, Rentz JJ, Neumayer LA, Pappas TN, Daley J, Henderson WG, Krasnicka B, Khuri SF. Outcomes after esophagectomy: a ten year prospective cohort. Ann Thorac Surg 2003;75:217 222.

11. Law SY, Fok M, Wong J. Risk analysis in resection of squamous cell carcinoma of the esophagus. World J Surg 1994;18:339 346 .

12. Bartels H, Stein HJ, Siewert JR. Preoperative risk analysis and postoperative mortality of oesophagectomy for resectable oeso phageal cancer. Br J Surg 1998;85:840 844.

13. Law S, Wong J. What is appropriate treatment for carcinoma of the thoracic esophagus? World J Surg 2001;25:189 195.

14. Orringer MB, Marshall B, Chang AC, Lee J, Pickens A, Lau CL. Two thousand transhiatal esophagectomies: changing trends, lessons learned. Ann Surg 2007;246:363 372.
15. Katariya K, Harvey JC, Pina E, Beattie EJ. Complications of transhiatal esophagectomy. J Surg Oncol 1994;57:157 163.

16. Hulscher JB, van Sandick JW, de Boer AG, Wijnhoven BP, Tijssen JG, Fockens P, Stalmeier PF, ten Kate FJ, van Dekken H, Obertop H, Tilanus HW, van Lanschot JJ. Extended transtho racic resection compared with limited transhiatal resection for adenocarcinoma of the esophagus. N Engl J Med 2002;347:1662 1669.

17. Omloo JM, Lagarde SM, Hulscher JB, Reitsma JB, Fockens P, van Dekken $H$, ten Kate FJ, Obertop $H$, Tilanus $H W$, van Lanschot JJ. Extended transthoracic resection compared with limited transhiatal resection for adenocarcinoma of the mid/distal esophagus: five year survival of a randomized clinical trial. Ann Surg 2007;246:992 1000.

18. Peyre CG, Hagen JA, DeMeester SR, Altorki NK, Ancona E, Griffin SM, Holscher A, Lerut T, Law S, Rice TW, Ruol A, van Lanschot JJ, Wong J, DeMeester TR. The number of lymph nodes removed predicts survival in esophageal cancer: an international study on the impact of extent of surgical resection. Ann Surg 2008;248:549 556.

19. Akaishi T, Kaneda I, Higuchi N, Kuriya Y, Kuramoto J, Toyoda T, Wakabayashi A. Thoracoscopic en bloc total esophagectomy with radical mediastinal lymphadenectomy. J Thorac Cardiovasc Surg 1996;112:1533 1540 .

20. Osugi H, Takemura M, Higashino $M$, Takada $N$, Lee $S$, Kinoshita H. A comparison of video assisted thoracoscopic oesophagectomy and radical lymph node dissection for squa mous cell cancer of the oesophagus with open operation. $\mathrm{Br} \mathrm{J}$ Surg 2003;90:108 113.

21. Law S. Minimally invasive techniques for oesophageal cancer surgery. Best Pract Res Clin Gastroenterol 2006;20:925 940.

22. Law S, Fok M, Chu KM, Wong J. Thoracoscopic esophagectomy for esophageal cancer. Surgery 1997;122:8 14.

23. Yamamoto S, Kawahara K, Maekawa T, Shiraishi T, Shirakusa T. Minimally invasive esophagectomy for stage I and II esophageal cancer. Ann Thorac Surg 2005;80:2070 2075.

24. Law SY, Fok M, Wei WI, Lam LK, Tung PH, Chu KM, Wong J. Thoracoscopic esophageal mobilization for pharyngolaryngoeso phagectomy. Ann Thorac Surg 2000;70:418 422.

25. Smithers BM, Gotley DC, McEwan D, Martin I, Bessell J, Doyle L. Thoracoscopic mobilization of the esophagus. A 6 year experience. Surg Endosc 2001;15:176 182.

26. Cuschieri A, Shimi S, Banting S. Endoscopic oesophagectomy through a right thoracoscopic approach. J R Coll Surg Edinb 1992;37:7 11.

27. Palanivelu C, Prakash A, Senthilkumar R, Senthilnathan P, Parthasarathi R, Rajan PS, Venkatachlam S. Minimally invasive esophagectomy: thoracoscopic mobilization of the esophagus and mediastinal lymphadenectomy in prone position experience of 130 patients. J Am Coll Surg 2006;203:7 16.

28. Nakatsuchi T, Otani M, Osugi H, Ito Y, Koike T. The necessity of chest physical therapy for thoracoscopic oesophagectomy. J Int Med Res 2005;33:434 441.

29. Bernabe KQ, Bolton JS, Richardson WS. Laparoscopic hand assisted versus open transhiatal esophagectomy: a case control study. Surg Endosc 2005;19:334 337.

30. Espat NJ, Jacobsen G, Horgan S, Donahue P. Minimally invasive treatment of esophageal cancer: laparoscopic staging to robotic esophagectomy. Cancer J 2005;11:10 17.

31. Luketich JD, Alvelo Rivera M, Buenaventura PO, Christie NA, McCaughan JS, Litle VR, Schauer PR, Close JM, Fernando HC. Minimally invasive esophagectomy: outcomes in 222 patients. Ann Surg 2003;238:486 494.

32. Peracchia A, Rosati R, Fumagalli U, Bona S, Chella B. Thoracoscopic dissection of the esophagus for cancer. Int Surg 1997;82:1 4 
33. Collard JM, Lengele B, Otte JB, Kestens PJ. En bloc and standard esophagectomies by thoracoscopy. Ann Thorac Surg 1993;56:675 679.

34. Cuschieri A. Thoracoscopic subtotal oesophagectomy. Endosc Surg Allied Technol 1994;2:21 25.

35. Bumm R, Feussner H, Bartels H, Stein H, Dittler HJ, Hofler H, Siewert JR. Radical transhiatal esophagectomy with two field lymphadenectomy and endodissection for distal esophageal adenocarcinoma. World J Surg 1997;21:822 831.

36. Kawahara K, Maekawa T, Okabayashi K, Hideshima T, Shiraishi T, Yoshinaga Y, Shirakusa T. Video assisted thoracoscopic esoph agectomy for esophageal cancer. Surg Endosc 1999;13:218 223.

37. Dexter SP, Martin IG, McMahon MJ. Radical thoracoscopic esophagectomy for cancer. Surg Endosc 1996;10:147 151.

38. Akaishi T, Kaneda I, Higuchi N, Kuriya Y, Kuramoto J, Toyoda T, Wakabayashi A. Thoracoscopic en bloc total esophagectomy with radical mediastinal lymphadenectomy. J Thorac Cardiovasc Surg 1996; $112: 15331540$.

39. Shiraishi T, Kawahara K, Shirakusa T, Yamamoto S, Maekawa T. Risk analysis in resection of thoracic esophageal cancer in the era of endoscopic surgery. Ann Thorac Surg 2006;81:1083 1089.

40. Taguchi S, Osugi H, Higashino M, Tokuhara T, Takada N, Takemura M, Lee S, Kinoshita H. Comparison of three field esophagectomy for esophageal cancer incorporating open or thoracoscopic thoracotomy. Surg Endosc 2003;17:1445 1450.

41. Nguyen NT, Follette DM, Wolfe BM, Schneider PD, Roberts P, Goodnight JE. Comparison of minimally invasive esophagectomy with transthoracic and transhiatal esophagectomy. Arch Surg 2000;135:920 925.

42. van den Broek WT, Makay O, Berends FJ, Yuan JZ, Houdijk AP, Meijer S, Cuesta MA. Laparoscopically assisted transhiatal resection for malignancies of the distal esophagus. Surg Endosc 2004; 18:812 817

43. Fukunaga T, Kidokoro A, Fukunaga M, Nagakari K, Suda M, Yoshikawa S. Kinetics of cytokines and PMN E in thoracoscopic esophagectomy. Surg Endosc 2001;15:1484 1487.

44. Bumm R, Holscher AH, Feussner H, Tachibana M, Bartels H, Siewert JR. Endodissection of the thoracic esophagus. Technique and clinical results in transhiatal esophagectomy. Ann Surg 1993;218:97 104.

45. Osugi H, Takemura M, Lee S, Nishikawa T, Fukuhara K, Iwasaki H, Higashino M. Thoracoscopic esophagectomy for intrathoracic esophageal cancer. Ann Thorac Cardiovasc Surg 2005;11:221 227.

46. Leibman S, Smithers BM, Gotley DC, Martin I, Thomas J. Minimally invasive esophagectomy: short and long term out comes. Surg Endosc 2005;203:428 433.

47. Osugi H, Takemura M, Higashino M, Takada N, Lee S, Ueno M, Tanaka Y, Fukuhara K, Hashimoto Y, Fujiwara Y, Kinoshita H. Learning curve of video assisted thoracoscopic esophagectomy and extensive lymphadenectomy for squamous cell cancer of the thoracic esophagus and results. Surg Endosc 2003;17:515 519.

48. Lo OS, Law S, Chu KM, Wong J. Chylothorax after esophagectomy. Surgery 2003;133:340 341

49. Hsu HK, Hsu WH, Huang MH. Prospective study of using fibrin glue to prevent leak from esophagogastric anastomosis. J Surg Assoc ROC 1992;25:1248 1252.

50. Whooley BP, Law S, Alexandrou A, Murthy SC, Wong J. Critical appraisal of the significance of intrathoracic anasto motic leakage after esophagectomy for cancer. Am J Surg 2001;181:198 203.

51. Holscher AH, Schneider PM, Gutschow C, Schroder W. Laparo scopic ischemic conditioning of the stomach for esophageal replacement. Ann Surg 2007;245:241 246.

52. Law S, Fok M, Chu KM, Wong J. Comparison of hand sewn and stapled esophagogastric anastomosis after esophageal resection for cancer: a prospective randomized controlled trial. Ann Surg 1997;226:169 173.

53. Orringer MB, Marshall B, Iannettoni MD. Eliminating the cervical esophagogastric anastomotic leak with a side to side stapled anastomosis. J Thorac Cardiovasc Surg 2000;119:277 288.

54. Lorentz T, Fok M, Wong J. Anastomotic leakage after resection and bypass for esophageal cancer: lessons learned from the past. World J Surg 1989;13:472 477.

55. Bartels H, Thorban S, Siewert JR. Anterior versus posterior reconstruction after transhiatal oesophagectomy: a randomized controlled trial. Br J Surg 1993;80:1141 1144.

56. Gawad KA, Hosch SB, Bumann D, Lubeck M, Moneke LC, Bloechle C, Knoefel WT, Busch C, Kuchler T, Izbicki JR. How important is the route of reconstruction after esophagectomy: a prospective randomized study. Am J Gastroenterol 1999;94:1490 1496.

57. van Lanschot JJ, van Blankenstein M, Oei HY, Tilanus HW. Randomized comparison of prevertebral and retrosternal gastric tube reconstruction after resection of oesophageal carcinoma. Br J Surg 1999;86:102 108.

58. Ngan SYK, Wong J. Lengths of different routes for esophageal replacement. J Thorac Cardiovasc Surg 1986;91:790 792.

59. Orringer MB, Marshall B, Iannettoni MD. Transhiatal esophagec tomy: clinical experience and refinements. Ann Surg 1999;230:392 400.

60. Ferri LE, Law S, Wong KH, Kwok KF, Wong J. The influence of technical complications on postoperative outcome and survival after esophagectomy. Ann Surg Oncol 2006;13:557 564.

61. Law S, Wong KH, Kwok KF, Chu KM, Wong J. Predictive factors for postoperative pulmonary complications and mortality after esophagectomy for cancer. Ann Surg 2004;240:791 800.

62. Baba M, Aikou T, Natsugoe S, Kusano C, Shimada M, Nakano S, Fukumoto T, Yoshinaka H. Quality of life following esophagec tomy with three field lymphadenectomy for carcinoma, focusing on its relationship to vocal cord palsy. Dis Esophagus 1998;11:28 34

63. Law S, Boey JP, Kwok KF, Wong KH, Chu KM, Wong J. Pleural drainage after transthoracic esophagectomy: experience with a vacuum system. Dis Esophagus 2004;17:81 86.

64. Whooley BP, Law S, Murthy SC, Alexandrou A, Wong J. Analysis of reduced death and complication rates after esophageal resection. Ann Surg 2001;233:338 344.

65. Tsui SL, Law S, Fok M, Lo JR, Ho E, Yang J, Wong J. Postoperative analgesia reduces mortality and morbidity after esophagectomy. Am J Surg 1997;173:472 478 .

66. Murthy SC, Law S, Whooley BP, Alexandrou A, Chu KM, Wong J. Atrial fibrillation after esophagectomy is a marker for postoperative morbidity and mortality. J Thorac Cardiovasc Surg 2003;126:1162 1167.

67. Lewis I. The surgical treatment of carcinoma of the esophagus with special reference to a new operation for growths of the middle third. Br J Surg 1946;34:18.

68. Freeman RK, Ascioti AJ, Wozniak TC. Postoperative esophageal leak management with the Polyflex esophageal stent. J Thorac Cardiovasc Surg 2007;133:333 338.

69. Law S, Suen DT, Wong KH, Kwok KF, Wong J. A single layer, continuous, hand sewn method for esophageal anastomosis: prospective evaluation in 218 patients. Arch Surg 2005;140:33 39.

70. Merrigan BA, Winter DC, O’Sullivan GC. Chylothorax. Br J Surg 1997;84:15 20.

71. Dimick JB, Pronovost PJ, Cowan JA, Lipsett PA. Surgical volume and quality of care for esophageal resection: do high volume hospitals have fewer complications? Ann Thorac Surg 2003;75:337 341 . 